Quim. Nova, Vol. 27, No. 1, 66-71, 2004

\title{
ANESTÉSICOS LOCAIS: INTERAÇÃO COM MEMBRANAS DE ERITRÓCITOS DE SANGUE HUMANO, ESTUDADA POR RESSONÂNCIA MAGNÉTICA NUCLEAR DE ${ }^{1} \mathrm{H}$ E ${ }^{31} \mathrm{P}$
}

\author{
Leonardo Fernandes Fraceto e Eneida de Paula* \\ Departamento de Bioquímica, Instituto de Biologia, Universidade Estadual de Campinas, CP 6109, 13083-970 Campinas - SP
}

Recebido em 2/4/03; aceito em 7/8/03

\begin{abstract}
LOCAL ANESTHETICS: INTERACTION WITH HUMAN ERYTHROCYTE MEMBRANES AS STUDIED BY ${ }^{1} \mathrm{H}$ AND ${ }^{31} \mathrm{P}$ NUCLEAR MAGNETIC RESONANCE. The literature carries many theories about the mechanism of action of local anesthetics (LA). We can highlight those focusing the direct effect of LA on the sodium channel protein and the ones that consider the interaction of anesthetic molecules with the lipid membrane phase. The interaction between local anesthetics and human erythrocyte membranes has been studied by ${ }^{1} \mathrm{H}$ and ${ }^{31} \mathrm{P}$ nuclear magnetic resonance spectroscopy. It was found that lidocaine (LDC) and benzocaine (BZC) bind to the membranes, increase the mobility of the protons of the phospholipid's acyl chains, and decrease the mobility and/or change the structure of the polar head groups. The results indicate that lidocaine molecules are inserted across the polar and liquid interface of the membrane, establishing both electrostatic (charged form) and hydrophobic (neutral form) interactions. Benzocaine locates itself a little deeper in the bilayer, between the interfacial glycerol region and the hydrophobic core. These changes in mobility or conformation of membrane lipids could affect the $\mathrm{Na}^{+}$-channel protein insertion in the bilayer, stabilizing it in the inactivated state, thus causing anesthesia.
\end{abstract}

Keywords: local anesthetic; Nuclear Magnetic Resonance; erythrocyte membrane.

\section{INTRODUÇÃO}

Anestésicos locais (AL) compreendem um grande número de moléculas, de diferentes estruturas químicas: amino-ésteres, amino-amidas, amino-cetonas, amidas, álcoois, tio-ésteres, tio-amidas, derivados de uréia, poliéteres, etc ${ }^{1}$, capazes de bloquear a condução do estímulo nervoso. Na clínica, amino-amidas como a lidocaína e a bupivacaína são os mais usados. Embora os amino-ésteres sejam, em geral, mais potentes que as amino-amidas ${ }^{2}$, a tendência atual é a de desenvolver-se aminoamidas mais potentes, pelo fato de serem menos tóxicas e mais resistentes à hidrólise, quando comparadas aos amino-ésteres ${ }^{3}$.

Por serem moléculas anfifílicas, os anestésicos locais têm grande afinidade pela membrana celular ${ }^{2}$. Podemos classificar as teorias propostas para explicar os mecanismos de ação destes compostos em duas categorias: a que atribui o efeito anestésico à ligação na proteína canal de sódio voltagem-dependente de axônios e a que considera a interação dos anestésicos locais com os lipídios da membrana (conhecida como "hipótese do lipídio") como o mecanismo responsável pelas alterações na proteína canal de sódio, levando ao bloqueio da condução do estímulo nervoso.

Em nosso laboratório temos estudado a interação de anestésicos locais com membranas modelo, tendo em vista as alterações estruturais e dinâmicas provocadas pelos anestésicos na fase lipídica ${ }^{4-8}$.

A literatura traz relatos da ação de anestésicos locais na diminuição da temperatura de transição de fases de lipídios, estudada por diferentes técnicas. Lee ${ }^{9,10}$, utilizando calorimetria diferencial de varredura, registrou diminuição da $\mathrm{T}_{c}$ de vesículas de fosfatidilcolina causada pela partição da benzocaína, procaína, tetracaína, lidocaína e dibucaína, em concentrações iguais às necessárias para $50 \%$ de bloqueio na condução do estímulo nervoso.

$\mathrm{O}$ fato de os AL perturbarem o empacotamento dos fosfolipídios em membranas modelo e biológicas foi bastante estudado por experimentos de ressonância paramagnética eletrônica (RPE) e outras

*e-mail: depaula@unicamp.br técnicas espectroscópicas, como ressonância magnética nuclear (RMN), infravermelho e fluorescência ${ }^{5}$, trazendo enorme contribuição para o entendimento da interação AL/membrana.

Através da técnica de absorção no infravermelho Schöpflin e colaboradores ${ }^{11}$ demonstraram a incorporação da dibucaína, procaína e dois outros AL em monocamadas de palmitoiloleil fosfatidilcolina, estudando as bandas de absorção dos compostos, entre 1400 e 1800 $\mathrm{cm}^{-1}$. A combinação de estudos de infravermelho com pressão possibilitou a Auger e colaboradores demonstrarem que a tetracaína, incorporada em membranas de fosfatidilcolina, fosfatidil serina e biológicas, é expulsa da bicamada por aumento da pressão ${ }^{12}$.

Os primeiros experimentos com RMN de hidrogênio $\left({ }^{1} \mathrm{H}-\mathrm{RMN}\right)$ detectaram imobilização da molécula do anestésico local, quando intercalado na bicamada lipídica ${ }^{13-17}$, efeito semelhante ao observado por RPE com análogos paramagnéticos dos $\mathrm{AL}^{18,19}$.

Ainda com ${ }^{1} \mathrm{H}-\mathrm{RMN}$ vários trabalhos mostraram a interação da forma protonada e da forma neutra dos anestésicos locais ${ }^{20-27} \mathrm{com}$ membranas fosfolipídicas.

Em nosso laboratório temos estudado a interação de anestésicos locais com membranas lipídicas, através de técnicas de RMN, RPE e fluorescência ${ }^{4,7,8}$. Para os anestésicos locais do tipo amino-amida: lidocaína, mepivacaína, bupivacaína e etidocaína, o efeito diferencial dos anestésicos locais sobre regiões da bicamada monitoradas por diferentes sondas paramagnéticas, alterações nos tempos de relaxação longitudinal dos lipídios em presença de anestésicos locais e interações intermoleculares específicas entre hidrogênios dos AL e lipídios forneceram evidências sobre a localização destes no interior da bicamada ${ }^{7,28}$.

Nakagawa e colaboradores ${ }^{29,30}$ estudaram a interação de dibucaína com "ghosts" de eritrócito de porco, utilizando ${ }^{1} \mathrm{H}-\mathrm{RMN}$ e ${ }^{31} \mathrm{P}-\mathrm{RMN}$. Observaram que a dibucaína interage com as membranas aumentando a mobilidade das cadeias acila e alterando a conformação da cabeça polar dos lipídios. Os autores mostraram assim, que a dibucaína se localiza entre a cabeça polar e as cadeias acílas dos lipídios, sendo tal localização mantida por interações eletrostáticas e hidrofóbicas. 
Segundo esses autores, as mudanças na mobilidade ou conformação dos lipídios seriam de grande importância no efeito causado pelo AL ao redor da proteína canal de sódio, levando-a ao estado inativado.

Neste trabalho comparamos os efeitos causados por dois anestésicos locais (Figura 1): lidocaína - uma amino-amida - e benzocaína - um éster - em membranas de eritrócito humano, utilizando técnicas de ${ }^{1} \mathrm{H}-\mathrm{RMN}$ e ${ }^{31} \mathrm{P}-\mathrm{RMN}$.

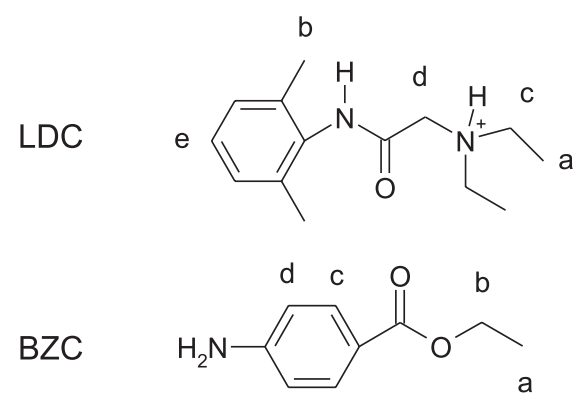

Figura 1. Estrutura química dos anestésicos locais e atribuição de picos de ${ }^{I} H-R M N$

\section{PARTE EXPERIMENTAL}

\section{Materiais e métodos}

A água deuterada, o cloridrato de lidocaína e a benzocaína usados nos experimentos foram adquiridos da Sigma Chem. Co. Todos os outros reagentes utilizados apresentavam grau analítico.

\section{Preparo das membranas de "ghosts"}

Bolsas de papa de hemácias foram obtidas do Hemocentro da Unicamp. As bolsas eram recentes - até 3 dias da data de coleta - e possuíam sorologia negativa para Chagas, sífilis, AIDS e hepatite B. As hemácias foram ressuspensas em solução hipotônica (tampão fosfato $5 \mathrm{mM}, \mathrm{pH} 8,0$ ) e levadas à centrifugação (900 $x$ g por $20 \mathrm{~min}$ ), procedimento repetido até se observar a precipitação de membranas esbranquiçadas, os "ghosts" de eritrócitos, obtidas pela lise das células e extravasamento do seu conteúdo interno ${ }^{31}$. Essas membranas esbranquiçadas foram lavadas com tampão fosfato $50 \mathrm{mM}$, pH 7,4 e estocadas em biofreezer $\left(\mathrm{a}-80^{\circ} \mathrm{C}\right)$. Para os experimentos de RMN de fósforo, o tampão fosfato $5 \mathrm{mM}$ foi substituído por tampão Tris. $\mathrm{HCl} 50 \mathrm{mM}, \mathrm{pH}$ 7,4.

A determinação da concentração proteica foi feita utilizando-se o método de Lowry ${ }^{32}$.

\section{Determinação do coeficiente de partição dos AL entre "ghosts"/tampão, por separação de fases}

As membranas de eritrócito foram preparadas como descrito anteriormente. Alíquotas de solução estoque dos AL, $1 \mathrm{mM}$ de benzocaína e $3 \mathrm{mM}$ de lidocaína, em tampão fosfato, foram adicionadas à suspensão de membranas, de modo a atingir leitura de absorção adequada a $284 \mathrm{~nm}\left(\varepsilon_{\mathrm{M}}=15850\right)$ e $262 \mathrm{~nm}\left(\varepsilon_{\mathrm{M}}=480\right)$, respectivamente para a $\mathrm{BZC}^{8}$ e LDC ${ }^{4}$. Após ultracentrifugação (120.000 $x$ g por $2 \mathrm{~h}$ ), determinou-se a concentração de anestésico livre no sobrenadante. A concentração de benzocaína e lidocaína na membrana foi calculada pela diferença entre a concentração do AL livre no sobrenadante e as concentração inicial. Conhecendo-se os volumes da fase aquosa lipídica, o coeficiente de partição $(\mathrm{P})$ foi calculado conforme a Equação 1.

$\mathrm{P}=(\mathrm{n} m / \mathrm{V} m) /(\mathrm{n} a / \mathrm{V} a)$
Os valores de n $m$ e na representam o número de moles de soluto na fase membranar e aquosa, respectivamente; $\mathrm{V}$ representa volume. $\mathrm{O}$ volume da fase lipídica (Va) foi calculado assumindo-se uma densidade de $1 \mathrm{~g} / \mathrm{mL}^{4,33}$.

\section{Experimentos de ${ }^{1} \mathrm{H}-\mathrm{RMN}$ e ${ }^{31} \mathrm{P}-\mathrm{RMN}$}

As medidas foram realizadas em espectrômetro Bruker DRX500 (500 MHz para ${ }^{1} \mathrm{H}$ e $202 \mathrm{MHz}$ para ${ }^{31} \mathrm{P}$ ), no Instituto de Química da Universidade de São Paulo. Os espectros de hidrogênio e fósforo foram obtidos com janelas de 12 ppm e 100 ppm, respectivamente, em sondas de $5 \mathrm{~mm}$. O número de aquisições no espectro de hidrogênio foi de 128 e no espectro de fósforo, 6000.

Para medidas de ${ }^{1} \mathrm{H}-\mathrm{RMN}$ os "ghosts", preparados como descri-

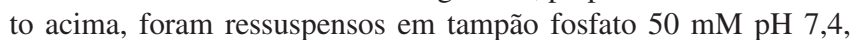
preparado em $\mathrm{D}_{2} \mathrm{O}$. A concentração de fosfolipídios utilizada nos experimentos foi de $5 \mathrm{mM}$, calculada a partir da relação molar proteína/lipídio de $1,1 / 1^{34,35}$, assumindo-se que a porcentagem de fosfolipídios nos lipídios totais é de $56 \%^{36}$ e tomando-se a massa molar média dos fosfolipídios (750) pela média ponderada da distribuição percentual dos mesmos na membrana de eritrócito ${ }^{30}$.

Nas amostras de ${ }^{31} \mathrm{P}-\mathrm{RMN}$ usamos concentrações de "ghosts" maiores (12 mM), dada a baixa sensibilidade deste núcleo e tampão TRIS-HCl $50 \mathrm{mM}$, preparado em água desionizada. Utilizou-se um capilar de $\mathrm{D}_{2} \mathrm{O}$, selado, para sintonia do equipamento de $\mathrm{RMN}$.

Para os experimentos de hidrogênio, adicionou-se o anestésico local ao "ghosts" na concentração de $3 \mathrm{mM}$ de fosfolipídios, enquanto nos experimentos de fósforo adicionou-se AL na concentração de $10 \mathrm{mM}$. As medidas foram feitas à temperatura de $30^{\circ} \mathrm{C}$.

\section{RESULTADOS E DISCUSSÃO}

\section{Medidas do coeficiente de partição por separação de fases}

Os valores de coeficiente de partição, determinados por separação de fases à temperatura ambiente, para o sistema "ghosts"/tampão foram de $303 \pm 105(\mathrm{n}=7)$ para a LDC e $287 \pm 76(\mathrm{n}=7)$ para a BZC, em pH 7,4 .

Entre lipossomas multilamelares de fosfatidilcolina de ovo e água, os valores de $\mathrm{P}$ para a lidocaína e para benzocaína, em $\mathrm{pH} 7,4$, são, respectivamente, $76^{37}$ e $253^{8}$.

Não foi encontrada na literatura descrição de valores de $\mathrm{P}$ entre membranas "ghosts"/água para os anestésicos estudados. Para o anestésico DBC o valor de P em "ghosts” de eritrócitos é de $375 \pm 62^{6}$, bem menor que o valor encontrado em lipossomas multilamelares de fosfatidilcolina $(2240 \pm 1050)^{4}$, mostrando que não é possível predizer o valor de $\mathrm{P}$ em membranas biológicas, pela simples comparação com os valores obtidos em membranas lipídicas. Enquanto a presença de proteínas faz diminuir consideravelmente a partição da dibucaína nas membranas de eritrócito, a lidocaína parece aumentar sua ligação à membrana e a benzocaína tem partição semelhante àquela observada em lipossomos. A maior partição da LDC entre "ghosts"/água indica haver interação entre o anestésico protonado e resíduos de aminoácidos das proteínas e/ou com lipídios carregados negativamente, da membrana do eritrócito. Já para a BZC, um AL que não se protona em pH fisiológico ${ }^{8}$, isto não aconteceu, levando a valores de coeficiente de partição muito semelhantes, nos dois tipos de membrana, "ghosts" e vesículas de fosfatidilcolina de ovo.

\section{${ }^{1} \mathrm{H}$ e ${ }^{31} \mathrm{P}$ RMN dos anestésicos e "ghosts"}

Os espectros de ${ }^{1} \mathrm{H}-\mathrm{RMN}$ dos AL e das membranas de "ghosts" podem ser vistos nas Figuras 2 e 3. A Tabela 1 mostra as atribuições 
e deslocamentos químicos dos hidrogênios desses AL, cuja estrutura química encontra-se na Figura 1. Os espectros foram referenciados ao pico da água residual - em 4,8 ppm - de forma a serem comparados com os experimentos em que se usou "ghosts".

O espectro das membranas de "ghosts" apresenta grande similaridade aos descritos na literatura ${ }^{29}$ e corresponde aos hidrogênios de lipídios e proteínas da membrana, além de uma pequena fração de proteínas residuais, dissolvidas no tampão mesmo após as repetidas lavagens das suspensões de "ghosts". A contribuição dessas proteínas contaminantes ao espectro da suspensão de "ghosts" é muito pequena e pode ser desconsiderada ${ }^{29}$. No espectro existem picos bastante alargados, quando comparados com os espectros de anestésicos, dada a grande sobreposição de sinais (haja visto o grande número de núcleos de hidrogênios diferentes), aliada à pouca mobilidade dos núcleos em sistemas membranares ${ }^{23,38}$. Se compararmos os espectros da Figura 2a e 2 c ou 3 a e $3 c$, observamos que nos espectros dos anestésicos (a) pode-se observar o acoplamento entre os hidrogênios vizinhos, que é perdido no espectro da suspensão de "ghosts" (c), justamente pela imobilização dos hidrogênios, neste último.

A atribuição de picos do espectro da suspensão de "ghosts" está de acordo com o descrito na literatura ${ }^{29}$ e está mostrada na Tabela 2.

O espectro do sistema "ghosts":LDC pode ser visto na Figura 2b. Através deste experimento concluímos que a molécula de lidocaína está inserida no interior das membranas, onde interage com lipídios e/ou com proteínas, visto que os picos observáveis de sua molécula estão alargados, isto é, imobilizados pela inserção entre os compo-

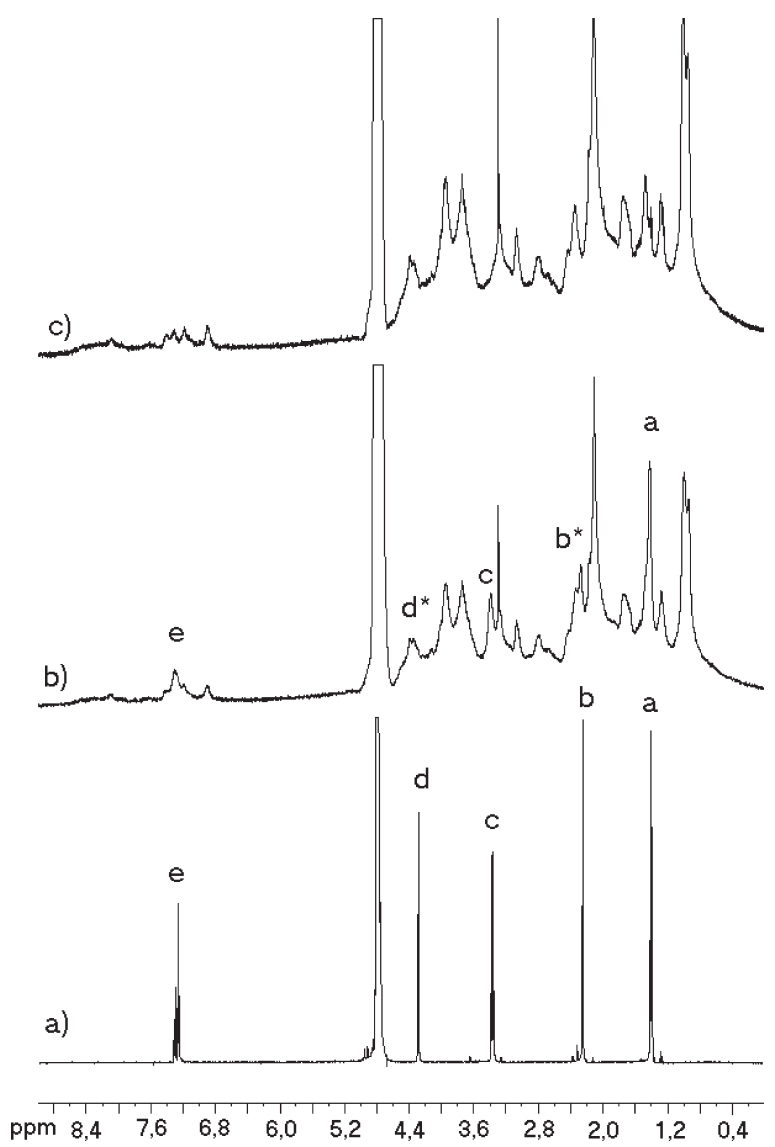

Figura 2. Espectro de ${ }^{1} H-R M N$ da: a) LDC (3 mM); b) "ghosts":LDC (5 mM:3 mM); c) suspensão de membranas de "ghosts" (5 mM), em pH 7,4 e $30{ }^{\circ} \mathrm{C}$. Espectro referenciado ao sinal da HDO residual (4,8 ppm), 500 $\mathrm{MHz}$. Os picos da LDC estão identificados por letras, os picos marcados com asteriscos estão sobrepostos a picos das membranas

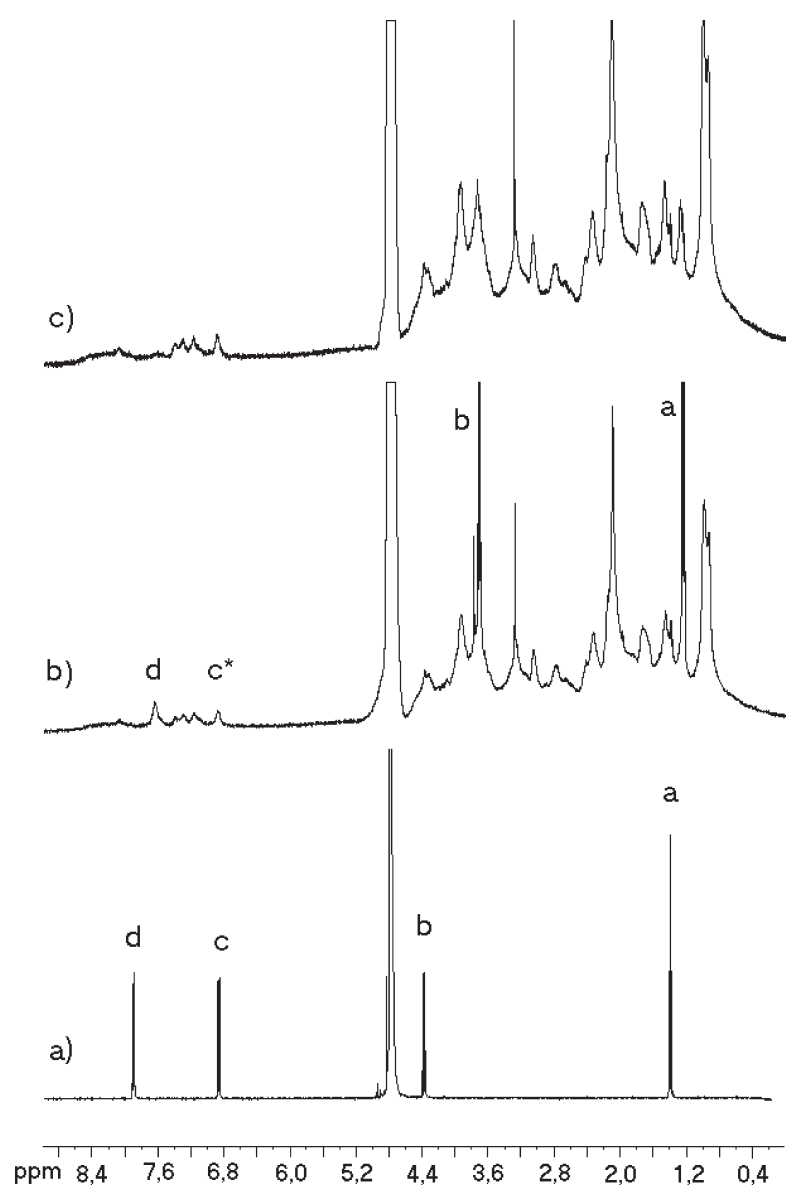

Figura 3. Espectro de ${ }^{1} H-R M N$ da: a) BZC (3 mM); b) "ghosts":BZC (5 mM:3 mM); c) suspensão de membranas de "ghosts" (5 mM), em pH 7,4 e $30{ }^{\circ} \mathrm{C}$. Espectro referenciado ao sinal da $\mathrm{HDO}$ residual $(4,8 \mathrm{ppm}), 500 \mathrm{MHz}$. Os picos da BZC estão identificados por letras, os picos marcados com asteriscos estão sobrepostos a picos das membranas

Tabela 1. Atribuição e deslocamentos químicos dos hidrogênios das moléculas de LDC e BZC. Os valores com asteriscos não foram obtidos por motivo de sobreposição espectral

\begin{tabular}{ccccc}
\hline Pico & \multicolumn{2}{c}{$\begin{array}{c}\text { Deslocamento químico } \\
\text { em água }(\mathrm{ppm})\end{array}$} & \multicolumn{2}{c}{$\begin{array}{c}\text { Deslocamento químico em } \\
\text { presença de "ghost" (ppm) }\end{array}$} \\
& LDC & BZC & LDC & BZC \\
\hline a & 1,38 & 1,40 & 1,38 & 1,23 \\
b & 2,26 & 4,38 & $*$ & 3,52 \\
c & 3,40 & 6,89 & 3,41 & $*$ \\
d & 4,30 & 7,93 & $*$ & 7,63 \\
e & 7,28 & - & 7,27 & - \\
\hline
\end{tabular}

nentes da bicamada. Com relação ao deslocamento químico, não foram encontradas variações maiores que $0,05 \mathrm{ppm}$ nos picos atribuídos ao anestésico ou aos componentes da membrana.

O espectro obtido para o sistema "ghosts”:BZC pode ser visto na Figura 3b. $\mathrm{O}$ alargamento dos picos atribuídos à benzocaína, em relação aos do anestésico em água, mais uma vez indica a inserção do anestésico na bicamada. Com relação ao deslocamento químico, com a benzocaína ocorreram algumas alterações: de 0,17 ppm para o pico a $\left(\mathrm{CH}_{3}\right.$-et), 0,86 ppm para o pico b $\left(\mathrm{CH}_{2}\right.$-et) e 0,30 ppm para o pico d (Ar 2,6), indicando que houve uma grande mudança no 
Tabela 2. Atribuição e deslocamento químicos dos hidrogênios das membranas de "ghosts"

\begin{tabular}{ccl}
\hline Deslocamento químico $(\mathrm{ppm})$ & Característica do pico & Atribuição \\
\hline 0,9 & Alargado & hidrogênios $\mathrm{CH}_{3}$ dos lipídios, colesterol e proteínas. \\
1,3 & Alargado & hidrogênios $\left(\mathrm{CH}_{2}\right)_{\mathrm{n}}$ da cadeia acila dos lipídios \\
2,2 & Alargado & hidrogênios $\mathrm{N}$-acetil, dos resíduos de açúcares e proteínas. \\
3,3 & Estreito & hidrogênios dos grupos colinas $\left(\mathrm{N}^{+}\left(\mathrm{CH}_{3}\right)_{3}\right)$ da cabeça polar dos lipídios \\
6,8 a 8,4 & Alargado & hidrogênios aromáticos, dos aminoácidos das proteínas de membranas \\
\hline
\end{tabular}

ambiente químico dos núcleos da porção linear $\left(\mathrm{CH}_{2}-\mathrm{CH}_{3}\right)$ e próximos ao grupamento éster da molécula do anestésico (Tabela 1).

As alterações no deslocamento químico dos hidrogênios da benzocaína, não observadas para a lidocaína, podem indicar uma inserção mais profunda da benzocaína no interior da bicamada lipídica (mudança no ambiente químico). De fato, estudos em vesículas multilamelares de fosfatidilcolina de ovo mostraram que a BZC se insere mais profundamente que a LDC na bicamada, distribuindo-se entre a região do glicerol e primeiros carbonos da cadeia acila dos fosfolipídios, diferentemente da LDC que estaria ancorada na cabeça polar dos lipídios ${ }^{7,8}$. Por medidas de tempo de relaxação longitudinal $\left(\mathrm{T}_{1}\right)$ em vesículas unilamelares de fosfatidilcolina de ovo mostramos que a LDC altera a mobilidade dos hidrogênios da cabeça polar dos lipídios, não tendo efeito pronunciado sobre aqueles do glicerol e primeiros carbonos da cadeia acila, onde a ordem da bicamada é máxima ${ }^{7}$. A maior liberdade de rotação dos hidrogênios da cabeça polar (região de maior mobilidade) poderia explicar a não observação de alterações no deslocamento químico dos hidrogênios da LDC (Tabela 1), inserida nesta porção da bicamada. Neste sistema, devido a não resolução e alargamento dos sinais do espectro de ${ }^{1} \mathrm{H}-\mathrm{RMN}$ de "ghosts" não se pode aplicar tal abordagem (medidas de $\mathrm{T}_{1}$ ), o mesmo acontecendo para medidas de efeito nuclear Overhauser (NOE), não são eficientes pois a relaxação dos hidrogênios leva a valores de NOE próximos a zero.

A partir dos valores de coeficiente de partição determinados para esses anestésicos no sistema "ghosts"/água calculamos a concentração destas no interior dos "ghosts", usando a Equação 1. Nas condições de ensaio (5 mM de "ghosts") 53\% da LDC e 52\% da BZC total adicionadas foram incorporadas à bicamada.

Tais dados mostram que as quantidades de anestésicos na membrana são praticamente as mesmas, ou seja, o efeito diferencial existente entre os dois anestésicos não se deve a quantidades diferentes na membrana e sim, a diferenças na interação destes com as membranas.

Considerando-se a carga positiva parcial da LDC em pH 7,4, podemos imaginar que as moléculas de LDC apresentam interação em uma região mais superficial da bicamada (Figura $2 b$ ), devido ao alargamento espectral provocado pela imobilização dos hidrogênios não acompanhado de mudanças no deslocamento químico de seus hidrogênios. Já para a BZC ocorreu tanto uma mudança na mobilidade de seus hidrogênios (alargamento) ao inserir-se nos "ghosts", quanto no deslocamento químico (ambiente químico) o que, aliado à sua carga neutra em pH fisiológico, justificaria uma inserção um pouco mais profunda no interior das bicamadas (Figura 3b).

Possivelmente a inserção mais superficial da LDC deva-se à grande fração de moléculas carregadas em $\mathrm{pH} 7,4^{4}$ que podem ser estabilizadas por cargas de proteínas e/ou lipídios carregados negativamente como a fosfatidilserina, fosfatidilinositol e ácido fosfatídico; tal estabilização justificaria uma imobilização da molécula, o que causaria um alargamento dos sinais dos picos da LDC.

Tais resultados estão de acordo com o perfil de inserção em vesículas multilamelares de fosfatidilcolina de ovo proposto por Pinto e colaboradores ${ }^{8}$, onde a BZC se insere mais profundamente (região entre glicerol e primeiros carbonos da cadeia acila) que a LDC. A inserção preferencial da LDC, em região próxima ao grupamento fosfato e cabeça polar encaixam-se perfeitamente bem com as evidências de localização deste AL em lipossomas de fosfatidilcolina de ovo ${ }^{7}$.

Para uma análise da região de interface entre a cabeça polar e o core hidrofóbicos da bicamada, foram realizados experimentos de ${ }^{31} \mathrm{P}-\mathrm{RMN}$. A Figura 4 mostra o espectro de ${ }^{31} \mathrm{P}$ dos fosfolipídios presentes na suspensão de "ghosts" em ausência (a) e presença dos anestésicos: lidocaína (b) e benzocaína (c).

No espectro dos "ghosts", podemos verificar um perfil para o

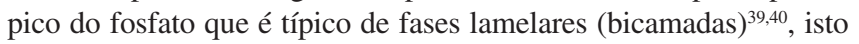
é, com um pico direito de alta intensidade e um "ombro" alargado em campo baixo. Este sinal anisotrópico reflete a orientação dos grupamentos fosfato dos fosfolipídios na bicamada. A medida do deslocamento químico anisotrópico, D.Q.A. (distância entre o pico de alta intensidade e o de campo baixo $)^{39}$, neste espectro foi de 35 ppm, o que está de acordo com os valores obtidos, em "ghosts", por Wakita e colaboradores ${ }^{29}$. Na Figura 4, o pico isotrópico observado em 0 ppm reflete os fosfatos livres em solução (fosfolipídios e/ou

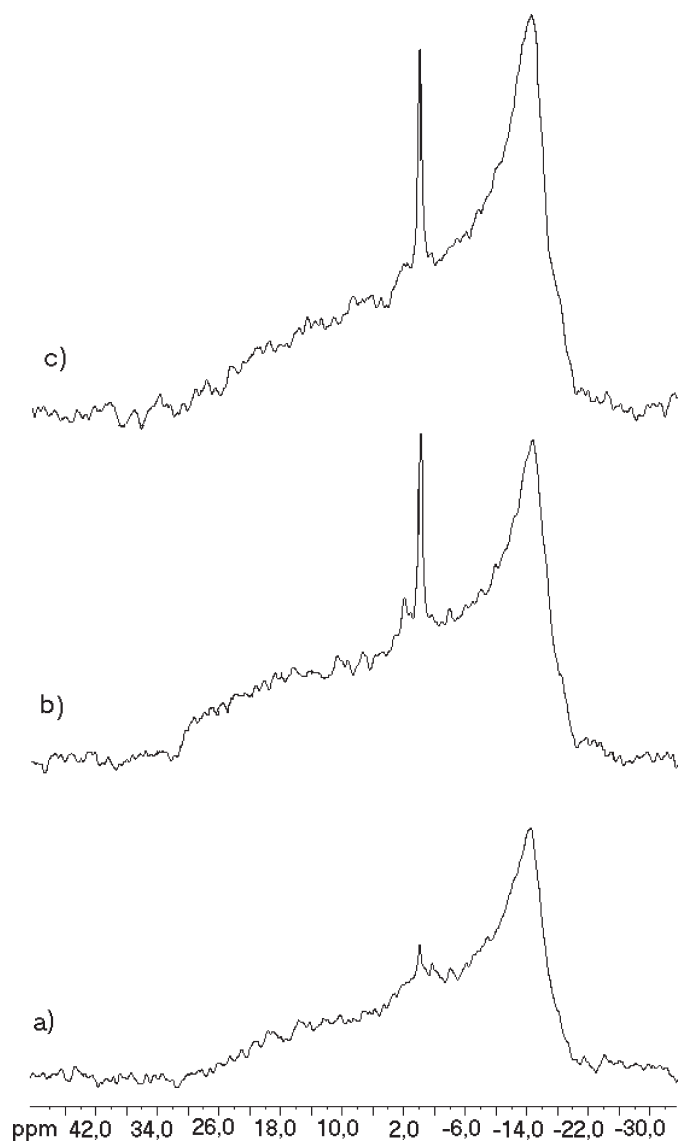

Figura 4. Espectro de ${ }^{31} P-R M N$ de suspensão de: a) "ghosts" (12 mM); b) "ghosts" em presença de LDC; c) "ghosts" em presença de BZC. Tampão TRIS-HCl $50 \mathrm{mM}, \mathrm{pH}$ 7,4. $202 \mathrm{MHz}$ e $30^{\circ} \mathrm{C}$ 
fosfato inorgânico) ou grupamentos fosfatos presentes em proteínas fosforiladas da membrana dos "ghosts" ${ }^{41}$.

Os experimentos em presença de anestésicos locais foram realizados para observar possíveis mudanças no D.Q.A., que refletiriam mudanças na ambiência química dos grupamentos fosfato (mobilidade ou orientação da cabeça polar dos lipídios) causadas pela inserção dessas moléculas na vizinhança do grupamento fosfato.

Os espectros de "ghosts" com LDC apresentam o mesmo perfil espectral mostrado na Figura 4a, indicando que a lidocaína não altera a organização lamelar dos lipídios para outro tipo de fase. No entanto, a medida de deslocamento químico anisotrópico na Figura $4 \mathrm{~b}$ foi de 40 ppm, mostrando que as moléculas de lidocaína diminuem a mobilidade dos grupamentos fosfato, causando mudanças conformacionais na cabeça polar dos fosfolipídios o que, como nos dados de ${ }^{1} \mathrm{H}-\mathrm{RMN}$, indica que a LDC tem localização preferencial nas regiões mais superficiais das bicamadas. Este efeito pode estar ocorrendo devido à perda de interações eletrostáticas entre as cabeças polares de fosfolipídios adjacentes e aumento da ordem local (região do grupamento fosfato), pela inserção da lidocaína com conseqüente aumento no deslocamento químico anisotrópico. Efeito parecido foi descrito na literatura pela interação de dibucaína em vesículas multilamelares de fosfatidilserina ${ }^{42} \mathrm{e}$ "ghosts" 29 , onde a interação eletrostática entre as moléculas de dibucaína carregadas e os grupamentos fosfato causaram diminuição na interação entre os fosfolipídios, gerando uma mudança conformacional na cabeça polar dos lipídios e aumento na ordem local, observada através de um aumento no deslocamento químico anisotrópico de ${ }^{31} \mathrm{P}-\mathrm{RMN}$.

Em vesículas multilamelares de fosfatidilcolina de ovo, Boulanger e colaboradore ${ }^{20}$ mostraram que a tetracaína, em sua forma protonada, causa uma alteração de até $8 \%$ no deslocamento químico anisotrópico do grupamento fosfato; segundo esses autores, as cargas positivas das moléculas de tetracaína estabilizariam as cargas negativas dos grupamentos fosfatos dos lipídios, justificando o efeito no sinal do grupamento fosfato.

A variação de $14 \%$ no deslocamento químico anisotrópico, provocado pela adição de lidocaína em $\mathrm{pH} 7,4$, indica a ligação das moléculas de LDC protonadas aos grupamentos fosfato, levando à estabilização de cargas e causando alterações conformacionais na cabeça polar dos fosfolipídios ${ }^{7}$ presentes na membrana de "ghosts".

A medida de deslocamento químico anisotrópico para os "ghosts" em presença de benzocaína foi de 33 ppm, variação não significativa e que indica que este anestésico não causa alteração na cabeça polar dos lipídios, provavelmente por se inserir em região mais profunda da bicamada, como evidenciado pelos dados de ${ }^{1} \mathrm{H}-\mathrm{RMN}$ e resultados anteriores de $\mathrm{RPE}^{8}$.

Um fato interessante é que houve um aumento no sinal isotrópico do fosfato na presença dos dois anestésicos (Figura 4). Este aumento pode ter sido causado por ação de fosfolipases presentes no meio e que, devido ao longo tempo dos experimentos, causariam o aparecimento de lisofosfolipídios e ácidos graxos livres, aumentando o sinal isotrópico do grupamento fosfato ${ }^{41,43}$.

Wakita e colaboradores ${ }^{29}$ encontraram, em membranas de "ghosts", um aumento de $11 \mathrm{ppm}$, ou seja, 32\% no deslocamento químico anisotrópico dos grupamentos fosfato, em presença de dibucaína. Esse efeito da dibucaína, bem maior que o encontrado para a LDC (14\%) reflete o volumoso anel quinolínico da dibucaína, que deve causar um maior espaçamento entre os fosfolipídios adjacentes na cabeça polar ao inserir-se naquela região da bicamada, como a lidocaína ${ }^{29}$. Estudos de modelagem molecular mostram que a LDC apresenta uma área de $433 \AA^{2}$ enquanto para a DBC este valor é de $617 \AA^{2}{ }^{1}$.

Um fato que deve ser levado em consideração é que grupos fosfato apresentam cargas negativas, que podem estabilizar cargas positivas dos anestésicos locais. Há na literatura vários relatos da competição de AL com íons cálcio, pela interação com grupamentos fosfato de vesículas lipídicas ${ }^{40,44}$. Desta forma, sabendo-se que a BZC não apresenta carga líquida em pH 7,4 justifica-se o fato deste $\mathrm{AL}$ não ter efeito sobre a cabeça polar, pois não tem como realizar interação

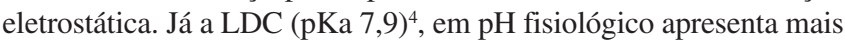
da metade das moléculas com carga positiva, possui efeito no sinal do grupamento fosfato. Se considerarmos que a dibucaína $(\mathrm{pKa} 8,3)^{4}$ tem, em $\mathrm{pH} 7,4$, ainda maior proporção de moléculas na forma protonada que a LDC, encontramos outro fator que justifica seu maior efeito sobre os grupamentos fosfato, visto que os coeficientes de partição destes três anestésicos têm valores muitos próximos, nos

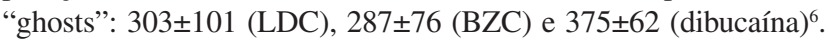

Um estudo anterior, em nosso laboratório, utilizando vesículas unilamelares de fosfatidilcolina de ovo e técnica de ${ }^{1} \mathrm{H}-\mathrm{RMN}$ mostrou, por determinação dos tempos de relaxação longitudinal, que a lidocaína desprotonada se localiza em uma região próxima ao grupamento fosfato da cabeça polar dos fosfolipídios ${ }^{7}$. Este fato reforça ainda mais a idéia de que moléculas de LDC com carga encontram-se na região próximas aos grupamentos fosfato dos fosfolipídios, estabelecendo interações eletrostáticas, que causam um grande efeito nesta região.

É importante destacar que esta localização é a preferencial, isto é, onde o AL deve se encontrar na maior parte do tempo. No entanto, não podemos esquecer que estas moléculas anfifílicas distribuem-se rapidamente entre a membrana biológica e a fase aquosa ${ }^{5}$, ou seja, apresentam um equilíbrio dinâmico, além da inserção preferencial no interior das bicamadas. Esta localização, determinada pelas interações do AL com os fosfolipídios deve ser determinante para a ação específica do AL em sítio(s) de ligação, na proteína canal de sódio ${ }^{45,46}$.

\section{CONCLUSÃO}

Os resultados aqui relatados mostram que lidocaína e benzocaína interagem em regiões diferentes das membranas de eritrócitos humanos, e que estes dados estão de acordo com experimentos prévios, com lipossomos de fosfatidilcolina de ovo $^{7,8}$, em que a LDC inserese próximo à cabeça polar, enquanto a $\mathrm{BZC}$ interage com regiões mais profundas da membrana de "ghosts". A localização destes anestésicos no interior das membranas biológicas pode ser um fator determinante para a interação destes com sítios hidrofóbicos na proteína canal de sódio ${ }^{45,46}$.

\section{AGRADECIMENTOS}

Os autores agradecem à FAPESP pelo auxílio financeiro (Proc. 96/01451-9) e bolsa de doutorado (L. F. Fraceto, Proc. 00/00362-0); ao CNPq pela bolsa de produtividade em pesquisa (E. de Paula, Proc. 300197/95-0) e a Dra S. Schreier e Instituto de Química/USP pelo uso do equipamento de RMN.

\section{REFERÊNCIAS}

1. Gupta, S. P.; Chem. Rev. 1991, 91, 1109

2. Covino, B. G.; Vassalo, H. G. Em Local Anesthetics: mechanisms of action and clinical use; Grune and Stratton: New York, 1976, cap. 3.

3. De Jong, R. H. Em Local Anesthetics; Thomas, C. C., ed.; Springfield: Illinois, 1994, cap. 2.

4. de Paula, E.; Schreier, S.; Biochim. Biophys. Acta 1995, 1240, 25.

5. de Paula, E.; Schreier, S.; Braz. J. Med. Res. 1996, 29, 877.

6. Malheiros, S. V. P.; Meirelles, N. C.; de Paula, E. ; Biophys. Chem. 2000, $83,89$.

7. Fraceto, L. F.; Pinto, L. M. A.; Franzoni, L.; Braga, A. A. C.; Spisni, A.; Schreier, S.; de Paula, E.; Biophys. Chem. 2002, 99, 229.

8. Pinto, L. M. A.; Yokaichiya, D. K.; Fraceto, L. F.; de Paula, E.; Biophys. Chem. 2000, 87, 213. 
9. Lee, A. G.; Biochim. Biophys. Acta 1976, 448, 34

10. Lee, A. G.; Biochim. Biophys. Acta 1978, 514, 95.

11. Schopflin, M.; Fingeli, U. P.; Perlia, X.; J. Am. Chem. Soc. 1987, 109, 2375

12. Auger, M.; Jarrel, H. C.; Smith, I. C. P.; Wong, P. T. T.; Siminovitch, D. J.; Mantsch, H. H.; Biochemistry 1987, 26, 8513.

13. Hauser, H.; Dawson, R. M. C.; Biochem. J. 1968, 109, 909.

14. Cerbon, J.; Biochim. Biophys. Acta 1972, $290,57$.

15. Darke, A.; Finer, E. G.; Flook, A. G.; Phillips, M. C.; J. Mol. Biol. 1972, $63,265$.

16. Finer, E. G.; Flook, A. G.; Hauser, H.; Biochim. Biophys. Acta 1972, 260, 49.

17. Lee, A. G.; Birdsall, J. M.; Levine, Y. K.; Metcalfe, J. C.; Biochim. Biophys. Acta 1972, 255, 43 .

18. Gargiulo, R. J.; Giotta, G. J.; Wang, H. H.; J. Med. Chem. 1973, $16,707$.

19. Giotta, G. J.; Chan, D. S.; Wang, H. H.; Arch. Biochim. Biophys. 1974 $163,453$.

20. Boulanger, Y.; Schreier, S.; Leitch, L. C.; Smith, I. C. P.; Can. J. Biochem. 1980, 58986

21. Boulanger, Y.; Schreier, S.; Smith, I. C. P.; Biochemistry 1981, 20, 6824

22. Westman, J.; Boulanger, Y.; Ehrenberg, A.; Smith, I. C. P.; Biochim. Biophys. Acta 1982, 685, 315.

23. Kuroda, Y. ; Kitamura, K.; J. Am. Chem. Soc. 1984, 106, 1.

24. Kelusky, E. C.; Smith, I. C. P.; Can. J. Biochem. Cell. Biol. 1984, 62, 178.

25. Kuroda, Y.; Fujiwara, Y.; Biochim. Biophys. Acta 1987, 903, 395.

26. Yokono, S.; Ogli, K.; Miura, S.; Ueda, I.; Biochim. Biophys. Acta 1989 982,300

27. Wakita, M.; Kuroda, Y.; Fujiwara, Y.; Nakagawa, T.; Chem. Phys. Lipids 1992, 62, 45

28. Fraceto, L. F.; Tese de Mestrado, Universidade Estadual de Campinas, Brasil, 2000
29. Wakita, M.; Kuroda, Y.; Nakagawa, T.; Chem. Pharm. Bull. 1992, 40, 1361 30. Kuroda , Y.; Wakita, M.; Nakagawa, T.; Chem. Pharm. Bull. 1994, 42, 2418

31. Dodge, J. R. C.; Mitchell, R. H.; Hanaban, D. J.; Arch. Biochem. Biophys. 1963, 100, 119.

32. Lowry, O. H.; Rosenberg, N. J.; Farr, A. L.; Randall, R. J.; J. Biol. Chem. 1951, 193, 265.

33. Lissi, E.; Bianconi, M. L.; Amaral, A. T.; de Paula, E.; Blanch, L. E. B.; Schreier, S.; Biochim. Biophys. Acta 1990, 1021, 46.

34. Dodge, J. R. C.; Mitchell, R. H.; Hanaban, D. J.; Arch. Biochem. Biophys. 1963, 100, 119.

35. Warren, R. C.; Physics and achitecture of cell membranes, Adam-Hilger: Bristol, 1987.

36. Sato, T.; Fujii, T.; Chem. Pharm. Bull. 1971, 19, 377.

37. Malheiros, S. V. P.; comunicação pessoal.

38. Holte, L. L.; Gawrisch, K.; Biochemistry 1997, 36, 4669.

39. Seelig, J.; Biochim. Biophys. Acta 1978, 515, 105.

40. De Kruijff, B.; van den Besselaar, A. M. H. P.; Cullis, P. R.; van den Bosch, H.; van Deenen, L. L. M.; Biochim. Biophys. Acta 1978, 514, 1.

41. van Meer, G.; De Krujiff, B.; Op den Kamp, J. A. F.; van Deenen, L. L. M.; Biochim. Biophys. Acta 1980, 596, 1.

42. Cullis, P. R.; Verkleij, A. J.; Ververgaert, P. H. J. Th.; Biochim. Biophys. Acta 1978, 513, 11.

43. Verkleij, A. J.; Zwasl, R. F. A.; Roelofsen, B.; Comfurius, P.; Kastelijn, D.; van Deenen, L. L. M.; Biochim. Biophys. Acta 1973, 323, 178.

44. Cullis, P. R.; Verkleij, A. J.; Biochim. Biophys. Acta 1979, 552, 546

45. Ragsdale, D. S.; McPhee, J. C.; Scheuer, R.; Catterall, W. A.; Science 1994, $265,1724$.

46. Ragsdale D. S.; McPhee J. C.; Scheuer, R.; Catterall, W. A.; Proc. Natl. Acad. Sci. U.S.A. 1996, 93, 9270. 